useful not only to neurologists, but also to internists, cardiologists, public health professionals, and others who deal with stroke.

The book begins with a review of statistical terminology, a potentially important topic for many neurologists. This is followed by a discussion of subtypes of stroke, which may be unnecessary for most neurologists, but serves as a good framework for nonneurologist health professionals who deal with stroke. The remainder of this book is organized into succinct chapters on all major risk factors for stroke (hypertension, diabetes, cardiovascular disease, tobacco abuse, etc.), with each chapter roughly divided into three sections: first, the risk factor's overall contribution to stroke incidence; second, a brief review of literature relating to interventions targeted at that risk factor (such as ALLHAT and HOPE in the chapter on hypertension); and third, specific suggestions regarding available medications and strategies to reduce stroke risk. In addition to well-established risk factors, there are also chapters dedicated to frequently encountered challenges, such as approach to cryptogenic stroke and calculation of periop- erative risk of stroke. Lastly, future tools of stroke prevention, such as endovascular therapies, genetic predisposition to stroke, and the role of serum biomarkers, are discussed to their current level of understanding.

My only criticism is that the chapter on diabetes should be expanded, given its overwhelming prevalence and its contribution to vascular disease. For example, while most other chapters briefly discuss the available options to treat a modifiable stroke risk factor, the chapter on diabetes offers few suggestions for management outside of describing a standard diabetic diet.

In summary, this book is an excellent review of stroke prevention, with concise overviews of pertinent literature and relevant suggestions regarding treatment, written in a very reader-friendly manner. It should serve as an excellent resource for neurologists and other professionals managing patients at risk for stroke.

Adam Kelly, MD

Copyright @ 2004 by AAN Enterprises, Inc.

\title{
Correction
}

\section{Monozygotic twins with tuberous sclerosis discordant for the severity of developmental deficits}

In the Brief Communication "Monozygotic twins with tuberous sclerosis discordant for the severity of developmental deficits" (Neurology 2004;62:795-798) by Humphrey et al., the authors have located two errors in the printed publication. The first is located in the Results section and the corrected sentence should read as follows: "Note that the numbers of images in Twin A is 25 and in Twin B 31, yet the size of tubers and extent of involvement of the brain in Twin A are clearly greater." The second is located in the Discussion section and the corrected sentence should read as follows: "It is also noteworthy that the nonautistic rather than the autistic twin developed infantile spasms."

The publisher apologizes for these errors. 


\section{Neurology}

\section{Monozygotic twins with tuberous sclerosis discordant for the severity of developmental deficits}

Neurology 2004;63;1764

DOI 10.1212/WNL.63.9.1764

This information is current as of November 8, 2004

\section{Updated Information \&}

Services

Permissions \& Licensing

Reprints including high resolution figures, can be found at: http://n.neurology.org/content/63/9/1764.full

Information about reproducing this article in parts (figures,tables) or in its entirety can be found online at:

http://www.neurology.org/about/about_the_journal\#permissions

Information about ordering reprints can be found online:

http://n.neurology.org/subscribers/advertise

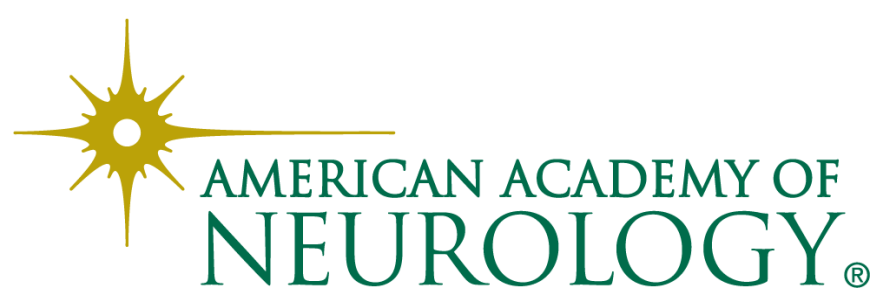

